\title{
Organização do trabalho, conflitos e agressões em uma emergência hospitalar na cidade de São Paulo, Brasil
}

\author{
Work organization, conflict and aggression in an \\ emergency hospital in São Paulo, Brazil \\ Selma Lancman', Rita Maria de Abreu Gonçalves², \\ Elisabete Ferreira Mângia ${ }^{3}$
}

\begin{abstract}
LANCMAN, S.; GONÇALVES, R. M. A.; MÂNGIA, E. F. Organização do trabalho, conflitos e agressões em uma emergência hospitalar na cidade de São Paulo, Brasil. Rev. Ter. Ocup. Univ. São Paulo, v. 23, n. 3, p. 199-207, set./dez. 2012.

RESUMO: As condições e processos de trabalho penosos dos pronto-socorros somados a elevada demanda frente à capacidade e gravidade dos casos, dificultam as decisões, impactam no atendimento e favorecem conflitos. Trata-se de um estudo de caso, exploratório e qualitativo, utilizou-se dados documentais, entrevistas semiestruturadas e observação do trabalho, especificamente dos porteiros. Objetivou-se verificar como características da organização do trabalho aumentam conflitos e agressões em um pronto-socorro comprometendo os atendimentos. Constatou-se que os porteiros estão na linha de frente e são expostos à pressão dos usuários por atendimento. Para solucionar conflitos, extrapolam regras e procedimentos, realizam tarefas além da sua competência, podendo alterar o fluxo e a qualidade do atendimento. Os arranjos organizacionais desconsideram os porteiros como parte da equipe de cuidados expondo-os a conflitos e agressões. Espera-se contribuir para mudanças, melhorar as relações, a segurança e o fluxo de atendimento.
\end{abstract}

DESCRITORES: Serviço hospitalar de emergência; Trabalho; Condições de trabalho; Relações interpessoais; Agressão; Estudos de casos; Serviços Médicos de Emergência/recursos humanos.

* Esse artigo é parte da pesquisa "O impacto da violência no trabalho e na saúde mental de trabalhadores de um serviço de emergência hospitalar”, financiada pela FAPESP e concluída em 2008 (Lancman S, Mangia EF. Relatório FAPESP, 2008, mimeo).

1. Profa. Dra. Titular do Departamento de Fisioterapia, Fonoaudiologia e Terapia Ocupacional da Faculdade de Medicina da Universidade de São Paulo.

2. Mestre em Ciências da Reabilitação pela Faculdade de Medicina da Universidade de São Paulo, especialista em ergonomia pela Escola Politécnica da Universidade de São Paulo, terapeuta ocupacional do Centro de Referência em Saúde do Trabalhador da Mooca da Prefeitura do Município de São Paulo.

3. Profa. Dra. do Departamento de Fisioterapia, Fonoaudiologia e Terapia Ocupacional da Faculdade de Medicina da Universidade de São Paulo.

Endereço para Correspondência: Rua Cipotânea, 51, Cidade Universitária São Paulo, SP, Brasil, CEP 05360 000. E-mail: lancman@usp.br 


\section{INTRODUÇÃO}

$\mathrm{O}$ $s$ novos processos trabalho caracterizamse pela intensificação e aumento das exigências, entre elas cognitivas e mentais que ignoram as características humanas, desestimulam à cooperação e as trocas interpessoais e adotam formas de avaliação baseadas em metas de produtividade e em desempenhos individuais mensuráveis, que desconsideram a qualidade e/ou a variabilidade do trabalho realizado (LANCMAN et al., 2009).

A precarização do trabalho e, sobretudo, a terceirização dos serviços determinam diferentes tipos de contrato, de vínculos e chefias para trabalhadores e setores que precisam trabalhar conjuntamente e onde o trabalho de um influencia e/ou depende do outro (DIAS, 2002). Com a terceirização o controle das condições, da organização do trabalho e dos cuidados da saúde e segurança dos trabalhadores ficam diluídos entre as empresas contratantes e os locais onde as pessoas efetivamente trabalham, ocorrendo, no final, uma desresponsabilização generalizada e os profissionais, muitas vezes, não sabem a quem se reportar.

O trabalho efetivamente realizado e as ações que os indivíduos fazem para realizar aquilo que não foi projetado, nem previsto, são desconsideradas como parte do processo de trabalho. Essa invisibilidade implica no não reconhecimento daquilo que, efetivamente, os sujeitos fazem e as estratégias que desenvolvem para atingir as metas da produção, as interações necessárias, as ações de prudência e zelo e, sobretudo, os riscos aos quais os trabalhadores estão submetidos, entre eles, os conflitos e agressões.

Os trabalhadores da saúde, pela natureza do seu trabalho, estão particularmente expostos a situações de elevado sofrimento e, é nas emergências que, a sobrecarga, o excesso de solicitação psicológica, a necessidade de soluções rápidas, o volume de atendimentos em relação à capacidade dos serviços, o contato com casos graves e usuários (pacientes, familiares e/ou acompanhantes) em momentos de grande tensão e sofrimento e a falta de procedimentos pré-estabelecidos adquirem maior destaque, podendo comprometer a saúde mental dos trabalhadores (GRAHAM; RAMIREZ, 1997; DESLANDES, 2002; SANTOS; DIAS, 2005).

A superlotação das emergências, os longos períodos de espera, a insatisfação e pressão para agilizar atendimentos, propiciam situações de elevada tensão, conflitos e agressões direcionados aos trabalhadores (ATKINSON, 1993; LANCMAN et al., 2009).
Entre as poucas publicações sobre violência no trabalho, El-Gilany et al. (2010) relatam conflitos e agressões dirigidas aos trabalhadores de serviços de emergências e destacam as áreas de psiquiatria, atendimento domiciliar e emergências como principais focos de violência. Kennedy (2005) ao estudar violência em emergências hospitalares e seus efeitos nos profissionais, aponta esses locais como os de maior risco para os trabalhadores. Constata que $100 \%$ da equipe de enfermagem experenciou ou testemunhou cenas de violência, relacionadas ao funcionamento desses locais.

Os trabalhadores da saúde são 16 vezes mais propensos a sofrerem violência no trabalho advindas de usuários e de colegas (GOOSNEY et al, 2009). Segundo a International Labour Organization (2002), os ambientes laborais com maior risco de violência estão concentrados no setor de serviços, entre eles, saúde, transporte e educação. Entre os fatores de risco estão: trabalho isolado; controle e exercício de autoridade; contato com clientes problemáticos em situações de grande tensão; organizações mal geridas que aumentam a insatisfação dos clientes e ações que desagradam os usuários por desacordarem de interesses individuais.

Arnetz e Arnetz (2001) constataram que as agressões aos profissionais de saúde partiam dos pacientes em $76 \%$ dos casos, $20 \%$ dos seus familiares e $9 \%$ de outros profissionais e que, a violência resultava das dificuldades de comunicação entre usuários e profissionais. Elevados índices de tensão no trabalho, altas demandas e longas jornadas de trabalho estão diretamente relacionados a danos à saúde mental dos trabalhadores (SUNDQUIST; JOHANSSON, 2000).

Os processos de gestão do trabalho devem considerar o impacto do trabalho na saúde e, em especial, na saúde mental, dos que estão na linha de frente da operacionalização e mais expostos a conflitos e agressões. É necessário desenvolver ações que protejam os trabalhadores, tanto individual quanto coletivamente (TOBIN, 2001). O desenvolvimento dessas ações não é evidente, nem automático, exige um alinhamento organizacional que indique soluções, diminua a exposição e possibilite soluções para que o trabalho seja realizado em melhores condições e segurança (LANCMAN et al., 2011).

\section{Características do Pronto Socorro do Hospital das Clínicas}

O Pronto Socorro do Hospital das Clínicas (P.S.), um dos mais importantes serviços públicos de referência para urgências clínicas, cirúrgicas e traumáticas, está situado em região central de São Paulo. O Hospital das Clínicas (HC), vinculado à Faculdade de Medicina da Universidade de São 
Paulo (FMUSP), é o maior complexo hospitalar da América Latina. O serviço atrai pacientes de diversas regiões da cidade, apesar da recente regionalização da assistência. A demanda em 2010 foi de 153.586 pacientes.

O P.S. é um serviço escola e conta, além da equipe fixa de atendimento, com profissionais responsáveis pelo ensino e alunos de vários cursos e níveis de aprendizado. Funciona 24 horas e é organizado por turnos. Os vários profissionais que compõem o corpo médico (assistentes, residentes, preceptores), a equipe de enfermagem, os porteiros, os profissionais de higiene e limpeza e os de apoio cumprem horários distintos e vinculam-se a chefias diferentes, algumas delas terceirizadas. Essas múltiplas formas de contrato e vínculos interferem na integração, na comunicação, na realização do trabalho e nas atribuições de cada um, gerando conflitos entre trabalhadores e entre trabalhadores e usuários que, muitas vezes, não sabem a quem se reportar.

O objetivo geral deste estudo é analisar as características e a organização do trabalho no P.S. e seus efeitos no processo de trabalho e no trabalhar. Buscava-se compreender de que maneira essa organização propicia situações de conflitos e agressões direcionadas aos trabalhadores podendo impactar na saúde deles e na qualidade do atendimento prestado.

Após a observação global da dinâmica do P.S., destacou-se um grupo específico de trabalhadores: os porteiros. Isso decorreu da constatação de que eles são, pela natureza do seu trabalho, um dos grupos mais suscetíveis e vulneráveis à coação dos usuários, a conflitos e agressões. Buscou-se identificar os tipos de pressão a que estão expostos, como lidam com a diversidade e a imprevisibilidade dessas situações e as estratégias utilizadas para definir ações, assegurar o fluxo de atendimento e preservar a sua integridade, saúde e segurança.

\section{MÉTODOS}

O estudo foi realizado em três etapas, que ocorreram de forma seqüencial e simultânea. Utilizou-se diferentes instrumentos de coleta e tratamento de dados que foram analisados concomitantemente às diferentes etapas da coleta. Essa estratégia permitiu referendar ou não os objetivos previamente traçados e redefini-los como desdobramento da abordagem inicial (TURATO, 2005; VASCONCELOS, 2002). A pesquisa foi financiada pela FAPESP e aprovada no Comitê de Ética do HC/FMUSP, protocolo $n^{\circ}$ 0063/08. Os participantes assinaram o termo de consentimento livre e esclarecido.

Inicialmente realizou-se um levantamento documental do número de atendimentos/ano; do trabalho prescrito dos diferentes profissionais; dos diversos fluxos de atendimento (casos graves, urgências, emergências) e entrevistas individuais com trabalhadores de diferentes níveis hierárquicos e categorias profissionais. Esse material não passou por nenhum tratamento analítico.

Numa $2^{\mathrm{a}}$ etapa realizou-se observações do trabalho do P.S. durante um período de sete dias consecutivos, considerados como uma semana típica. Nessa ocasião três equipes compostas cada uma por quatro observadores, divididas em três períodos de 8 horas, fizeram 168 horas de observações ininterruptamente. Os observadores se posicionaram em locais estratégicos como a portaria, as portas da sala de atendimento, o posto de enfermagem, a sala de espera, entre outros. Foram elaborados cadernos de campo que reuniram registros das observações, reflexões sobre o trabalho e interações das pessoas e outros aspectos relevantes para a compreensão do contexto estudado. Esse material foi analisado segundo o registro de cada observador e, posteriormente, pela sistematização e interação dos conteúdos, subsidiando maior aproximação com o campo.

Essas duas etapas possibilitaram realizar um primeiro diagnóstico situacional que identificou que os porteiros, por estarem na linha de frente (porta de entrada do P.S.), é um dos segmentos profissionais mais expostos às pressões por presteza no atendimento e acesso ao hospital. Pressão essa exercida, por vezes, através de conflitos e agressões, oriundas dos usuários. A seguir, desenvolveu-se numa $3^{\mathrm{a}}$ etapa, estudo específico do trabalho desses profissionais através de seis entrevistas individuais semi estruturadas e observações abertas, visando compreender o trabalho real e os constrangimentos a que estão expostos. Diversificou-se os trabalhadores observados, os horários e dias da semana.

Para compreender a defasagem entre trabalho prescrito e real e subsidiar as entrevistas e observações, utilizou-se os princípios teórico metodológicos da ergonomia francobelga, que pressupõe que o trabalho prescrito é invariavelmente diferente do real. O primeiro refere-se ao que é solicitado ao trabalhador e engloba, os objetivos a serem atingidos, os procedimentos, os meios técnicos a serem utilizadas, a divisão de tarefas e as condições temporais, sociais e ambientais de trabalho. Já o trabalho real, a atividade, envolve as ações, as decisões, as estratégias operatórias utilizadas para atingir ou redefinir os objetivos e metas, de acordo com as condições reais. Os trabalhadores utilizam seu corpo, sua inteligência e sua experiência para realizar o solicitado (GUERIN et al, 2001; ABRAHÃO et al, 2009) 


\section{RESULTADOS}

As condições e a organização do trabalho incidem diretamente sobre os trabalhadores e a qualidade do trabalho, entre eles destacamos os recursos humanos, materiais e o espaço físico.

Trabalham no P.S., entre outros, médicos assistentes, preceptores da residência médica e residentes; enfermeiros e auxiliares de enfermagem; agentes administrativos; porteiros e auxiliares de higiene e limpeza.

Os dados referentes aos processos de trabalho, número de trabalhadores, jornada e tarefas realizadas foram levantados a partir de entrevistas com diretorias, chefias, supervisores e trabalhadores diversos.

Tabela 1. Categorias Profissionais entrevistadas, número de trabalhadores por categoria, jornada de trabalho e situação de trabalho

\begin{tabular}{|c|c|c|c|}
\hline Cargo / função & $\begin{array}{c}\mathrm{N}^{0} \text { de } \\
\text { trabalhadores } \\
\end{array}$ & Jornada de trabalho & Trabalha sozinho ou em equipe \\
\hline Médico residente (R1) & 30 & $\begin{array}{l}12 \times 24 \text { hs no P.S e algumas horas no } \\
\text { ambulatório }\end{array}$ & Dependendo do setor trabalha sozinho \\
\hline Enfermeiro & 34 & $\begin{array}{l}8 \mathrm{hs} / \text { dia ou } 6 \mathrm{hs} / \text { dia (completam com um } \\
\text { plantão de } 12 \mathrm{hs} \text { ) }\end{array}$ & Dependendo do setor trabalha sozinho \\
\hline Auxiliar de enfermagem & 180 & $12 \mathrm{hs} / \mathrm{dia}(12 / 36 \mathrm{hs})$ ou $8 \mathrm{hs} / \mathrm{dia}$ & Dependendo do setor trabalha sozinho \\
\hline Auxiliar administrativo & 17 & 8hs (diurno) e 12 hs (noturno $-12 / 36 \mathrm{hs)}$ & A noite o trabalho é em equipe \\
\hline $\begin{array}{l}\text { Auxiliar de higiene e } \\
\text { limpeza }\end{array}$ & 8 & $8 \mathrm{hs} / \mathrm{dia}$ & Dependendo do setor trabalha sozinho \\
\hline Porteiro & 6 & 12hs/dia (4 dias consecutivos) & Trabalha sozinho \\
\hline Segurança e zeladoria & 9 & $12 \mathrm{hs} / \mathrm{dia}(12 / 36 \mathrm{hs})$ & Trabalham em dupla \\
\hline
\end{tabular}

As várias equipes de cuidado, de apoio e de administração estão submetidas a diferente chefias e hierarquias, pouco articuladas e, embora compartilhem responsabilidades na assistência e na manutenção do P.S., há fragmentação, falta de comandos unificados e relações de paralelismo na realização do trabalho.

$\mathrm{O}$ espaço físico é insuficiente e inadequado às ações, ao volume de atendimentos e aos recursos materiais (equipamentos, aparelhos de RX, de ventilação artificial, etc). Os pacientes, a espera de atendimento, permanecem longos períodos, em cadeiras e macas dispostas nos corredores - inclusive em frente às salas de cuidados e dos banheiros - e são insuficientes tanto para os pacientes quanto para os acompanhantes. Verificou-se ainda, que a maioria dos atendimentos ocorre no corredor. Esse corredor dá acesso à rua sendo utilizado por funcionários de outros setores do hospital como passagem, ocasionando intenso fluxo de pessoas, por vezes, alheias ao setor.

Esse ambiente produz a situação basal geradora de conflitos entre trabalhadores e entre usuários e profissionais. As situações de gravidade necessitam de respostas rápidas e ágeis e a lentidão dos atendimentos expõe os trabalhadores a um circuito exaustivo de solicitações e demandas que eles não conseguem atender, gerando situações de pressão, conflitos e agressões.

\section{Os Porteiros}

Os porteiros, apesar de serem fundamentais no fluxo de atendimento do P.S, levados em conta na organização do trabalho. Eles são terceirizados e têm suas atividades pouco planejadas, equacionadas e/ou entrosadas com os demais. São seis porteiros, todos do sexo masculino e com 11 anos de escolaridade, trabalham sozinhos, 12 horas por dia (em turnos diurno e noturno), a escala é de quatro dias de trabalho por dois de folga.

As tarefas prescritas são genéricas, referem-se a todas as portarias do $\mathrm{HC}$ e compreendem: auxiliar no controle e fluxo de usuários e funcionários; controle de equipamentos; manter a organização dos corredores próximos a portaria, orientando os acompanhantes; informar aos pacientes sobre o local de atendimento, além de proibir a entrada de alimentos.

Os porteiros relataram que no início foram orientados verbalmente pelo supervisor - funcionário da empresa terceirizada responsável pelas portarias do hospital - sobre os principais procedimentos e normas. 
Começaram a trabalhar no P.S. sem treinamento específico, capacitação e/ou supervisão, nem experiência prévia em hospital. Como a empresa contratante oferece serviços para diferentes setores (bancário, educação, entre outros), os terceirizados não sabem previamente onde irão trabalhar.

O trabalho real engloba: separar as fichas dos pacientes colocando-as em caixas segundo cada especialidade médica; auxiliar pacientes a encontrarem local para sentar; esclarecer os usuários quanto a demora do atendimento; bloquear o acesso de pessoas que querem entrar no hospital pelo P.S.; acalmar pessoas que chegam muito nervosas em busca de informação sobre pacientes; orientar os usuários quanto ao local para onde devem se dirigir; agilizar o atendimento quando chega alguma emergência; por vezes, ajudam a transportar pacientes do carro para a maca e a depender da gravidade do caso, para as salas de atendimento; prestar atenção a tudo e a todos; memorizar os usuários que estão no P.S., controlar a evasão, o roubo de equipamentos; orientar pacientes que querem se alimentar, mas que necessitam ficar em jejum. Por vezes, acabam triando, quem poderá entrar e ser atendido ou não. A diversidade de atribuições pode ser exemplificada em algumas afirmações deles:

Uma dificuldade é ter que triar as pessoas. (Ent.1) Tem que prestar atenção se o paciente não está saindo com o acesso no braço (Ent.4)

A porta do P.S. fica o tempo todo aberta, fica difícil controlar as pessoas". (Ent.5)

Tenho que ficar em pé para segurar a cancela, senão as pessoas entram ou para segurar pacientes que querem fugir". (Ent.2)

Pressionados pelos usuários ou por compaixão, burlam as normas, quando, por exemplo, chega um paciente em estado grave, e eles deixam o acompanhante entrar. Esses procedimentos, embora em desacordo com as orientações recebidas, aliviam situações de tensão e servem como estratégia de proteção aos trabalhadores.

Libero algumas pessoas para entrar, para não ficar tão estressado, porque estressa". (Ent.6)

É preciso ter bom senso em relação às normas, ter jogo de cintura e agir rápido. (Ent.3)

Esse grupo, pelas características do seu trabalho, serve de anteparo entre os usuários e a instituição, no entanto, ficam expostos a diversas formas de conflitos e agressões geradas pelas pessoas que forçam a entrada ou tentam burlar normas para serem atendidos ou obterem informações. Essas situações também podem impactar na saúde mental deles, pelo medo que essas agressões suscitam, pela tensão cotidiana vivenciada, ou ainda pelo contato intenso e sem nenhum preparo com situações de elevado sofrimento.

... de todos as portarias eu acho que, para nós, é o ponto mais crítico. (Ent.1)

Na minha visão, trabalhar no P.S. é uma punição, pelo stress que é (Ent.5)

É o local mais crítico, pelo fluxo de pessoas, pelas emergências, pelo nervosismo. Ocasiona stress, há possibilidade de agressão, contato com o sofrimento, com doenças infecciosas. (Ent.2)

Os porteiros, responsáveis pelo controle e pela regulação do acesso e permanência de usuários, são alvos de vários tipos de ameaças e agressões tanto de usuários quanto de outros trabalhadores. Não receberam treinamento apropriado para lidar com essas situações e dispõem de poucos recursos ou apoio de outros trabalhadores.

Sem tem discussão a gente fica muito abalado, não sabe se a pessoa vai voltar...você chega em casa estressado e descarrega na família... é muita gente pedindo informação, muita ignorância no dia a dia, fico 4 dias direto $12 \mathrm{hs}$ ". (Ent.2)

Na porta, direto, somos ameaçados, sinto medo de ser agredido". (Ent.5)

Xingar é direto, ai tento me controlar, mas é dificil, porque a gente é humano". (Ent.4)

Dois acompanhantes partiram pra cima de mim, fiquei em pânico, a gente não pode agredir a pessoa, tenta se defender mas, as vezes, é difícil. (Ent.6)

A gente fica abatido, devido a violência que a gente sofre. (Ent.4)

Fui agredido por um segurança que era meu parceiro, ele tava alterado, levei um murro... é devido a muito agito, às vezes, a pessoa fica meio alterada" (Ent.1)

...eles vem com o fogo e a gente é que nem água, tem que apagar. (Ent.3)

A falta de formação em saúde também os leva a temerem e a não saberem distinguir nem lidar com algumas doenças que entendem ser contagiosas. Por iniciativa própria imitam procedimentos que outros profissionais realizam. 
"Tenho medo de me contaminar devido ao contato com os pacientes". (Ent.1)

É estressante devido a proximidade dos pacientes, traz contato com doenças contagiosas. (Ent.2) Faço higienização das mãos por conta própria, vendo o que os outros fazem". (Ent.5)

Trata-se de um grupo mais identificado com o sofrimento e necessidades dos usuários, o que os leva a atitudes de cumplicidade e cooperação. Destacam-se situações onde diferenciam condutas, tanto movidos por compaixão quanto pelo julgamento que fazem de alguma prioridade ou gravidade. Embora, alguns deles desenvolvam um distanciamento defensivo do contato com o sofrimento dos pacientes, algumas situações extrapolam essas defesas e interferem no tempo do não trabalho.

"Uma coisa que bateu muito forte, foi ter que empurrar uma maca com uma senhorinha que acabou morrendo... foi marcante... não tinha ninguém para ajudar. (Ent.4)

Tem umas coisas que a gente vê e tem que fazer o possivel para esquecer, tem coisas que marcam. (Ent.6)

Aprendi a ser mais humano, não que eu não era tão humano... dou mais valor a vida. (Ent.2)

No começo ficava muito impressionado com o que via, câncer, acidentados, gente baleada, cada cena feia, ficava pensando naquilo o dia todo quando chegava em casa... a gente acostuma, fica mais frio, sem emoção. (Ent.5)

Já não me abalo mais com essas coisas...me sensibilizo, mas não me abalo. (Ent.3)

Eles são o principal anteparo entre os usuários e a instituição e acabam triando o acesso ao P.S. Paradoxalmente, apesar do excesso de pressões que sofrem, são pouco preparados e respaldados pela organização que protegem, utilizam recursos próprios para sobreviverem psiquicamente e continuarem a trabalhar. Desenvolvem estratégias individuais para realizarem o trabalho e para se protegerem. Soma-se a isso a exposição permanente a usuários graves: eles assistem a situações dramáticas sem disporem dos recursos e treinamentos dos profissionais da saúde. Esses trabalhadores são um dos grupos que mais sofre impactos psicológicos pelas situações que presenciam e vivenciam durante seu trabalho.

\section{DISCUSSÃO}

Para os trabalhadores do P.S. o processo de trabalho se caracteriza pela sobrecarga; individualização dos processos de responsabilização; falta de tempo para decisões, espaços para trocas de experiências e cooperação. As pressões pela agilização dos atendimentos são frequentes, além de disputa por recursos e melhor divisão de atribuições e responsabilidades. Os trabalhadores estão habituados a essa dinâmica e à elevada quantidade da demanda com a qual interagem e que parece estar incorporadas às suas rotinas.

Os turnos e jornadas de trabalho dos diversos profissionais são múltiplos, dificultando a comunicação e os vínculos. Há, ainda, falta de coordenação e entrosamento do processo de trabalho de cada equipe que respondem a chefias distintas. Dias (2002) relata que a existência de diferentes vínculos e chefias e a terceirização dos serviços dificultam a comunicação e a integração entre os diversos profissionais como também os processos de mediação do trabalho. Lancman et al. $(2011,2012)$ identificaram também pouca cooperação intraequipes e entre equipes, individualização dos processos decisórios e pouco espaço para trocas e compartilhamento de experiências entre os trabalhadores de uma emergência hospitalar.

Os porteiros estão entre os mais vulneráveis às pressões exercidas pelos usuários por atendimento, estão expostos cotidianamente, sem anteparo, às situações de intenso sofrimento dos usuários. Testemunham casos graves, interagem com acompanhantes fortemente impactados. A falta de preparo e formação em saúde faz com que tenham que produzir repertório próprio e estabelecer estratégias e critérios para resolução destas situações. São hábeis negociadores, porém operam com critérios próprios fruto da sua experiência, mas que transcendem a sua capacitação na área de saúde podendo comprometer o fluxo dos atendimentos.

Essa dinâmica é comum a outras categorias profissionais, como aponta Melo et al. (2007) em estudo realizado com pediatras de um serviço de emergência onde constata eles desenvolvem estratégias informais para lidar com o excesso de demanda e garantir a qualidade do atendimento.

Gonçalves (2009) refere que no setor de serviços de saúde, os trabalhadores representam a instituição diante ds usuários e terminam sendo anteparo, o que pode trazer consequências diretas e indiretas, não apenas para a qualidade do trabalho como também, para os trabalhadores 
e os usuários.

$\mathrm{O}$ excesso de casos e a falta de infraestrutura correspondente retardam os atendimentos, irritando os usuários que cobram, dos funcionários mais próximos, maior resolutividade. Situações como, o desespero daqueles que necessitam de atendimento urgente, geram o descumprimento dos regulamentos e deflagram, muitas vezes, ameaças e agressões contra os trabalhadores, como se eles fossem responsáveis pelos problemas e dispusessem de meios para resolvê-los.

Estudos realizados pela International Labour Organization (2002) e El-Gilany et al. (2010) apontam que os trabalhadores da saúde estão mais propensos a vivenciarem constrangimentos, conflitos e agressões por parte dos usuários e até mesmo dos colegas de trabalho. Tal situação que se agrava quando as instituições são mal geridas, os usuários são problemáticos e ocorrem situações de tensão com frequência.

Atkinson (1993), Graham e Ramirez (1997), Deslandes (2002), Santos e Dias (2005), Kennedy (2005), Lancman et al. (2009) afirmam que as situações de pressão, conflitos e agressões geradas pelos usuários dos serviços de emergência sobre os trabalhadores podem comprometer a qualidade do trabalho prestado e a saúde mental dos trabalhadores.

Os porteiros, um dos grupos mais suscetível a esses fatores, trabalham sem preparo ou orientação e, por serem terceirizados, nem a empresa contratante, nem a contratada se responsabilizam pelos treinamentos, nem por soluções organizacionais que melhorem o desenvolvimento do trabalho. A possibilidade de rodízio de local é quase inexistente, pois os demais trabalhadores não querem vir trabalhar no P.S.

As características organizacionais do P.S. interferem diretamente no trabalho deles e eles no fluxo de atendimento. Por não serem considerados parte integrante da equipe de apoio, seu trabalho não é pensado como parte integrante desse fluxo. Para a melhoria do serviço como um todo, e do trabalho dos porteiros, é importante considerar, entre outros fatores, a integração das equipes, a comunicação, o entrosamento entre trabalhadores de diferentes funções e vínculos empregatícios e a adequação dos recursos humanos e materiais. A instituição necessita desenvolver ações que protejam os trabalhadores, tanto individual quanto coletivamente.

Schraiber et al. (1999) e Coelho e Jorge (2009), ao estudarem serviços públicos de saúde, destacam a importância do investimento em aspectos organizacionais, tais como, planejamento e gestão da produção e melhoria da intercomunicação, acesso à informação, além do desenvolvimento de relações efetivas de trabalho e de melhorias no atendimento. Colares e Freitas (2007) apontam a obrigatoriedade dos gestores de criarem espaços para a participação dos trabalhadores em mudanças nos processos organizacionais.

Trad e Rocha (2011) afirmam que fragilidades de infraestrutura e o pouco investimento em formação das equipes dificultam os princípios da humanização em saúde, apesar de constatarem um alto grau de sensibilidade dos profissionais pelas necessidades e problemas da população atendida.

\section{CONCLUSÃo}

O estudo corrobora os resultados de várias pesquisas realizados no setor de serviços de saúde, especificamente, nas emergências hospitalares, que apontam que os trabalhadores estão expostos diariamente e cotidianamente, a uma gama de constrangimentos relacionados à elevada demanda frente à capacidade de atendimento e a gravidade dos casos o que dificulta a tomada de decisões, individualiza as responsabilidades e causa impacto nos atendimentos, favorecendo a ocorrência de conflitos e agressões, principalmente, dos usuários dos serviços e seus acompanhantes contra os trabalhadores. A vivência de tais situações pode trazer consequências para a saúde dos trabalhadores.

Espera-se com esse estudo contribuir na proposição de mudanças, principalmente das características da organização do trabalho como o investimento na melhoria da comunicação e das relações interpessoais entre as intre e entrequipes; em supervisão, capacitações dos trabalhadores dos diversos setores principalmente, dos que estão na linha de frente como porteiros e seguranças que também fazem parte indiretamente da equipe de cuidados.

Pretende-se ainda, contribuir para que a instituição analise os aspectos da organização do trabalho que aumentam as pressões sofridas pelos trabalhadores a fim de diminuir o risco de conflitos e agressões, e simultaneamente adote medidas de proteção à integridade, saúde e segurança dos trabalhadores. Uma vez que, o investimento em mudanças positivas das condições e da organização do trabalho gera melhorias da qualidade da assistência prestada aos usuários dos serviços e consequentemente, traz benefícios à saúde dos trabalhadores. 
LANCMAN, S.; GONÇALVES, R. M. A.; MÂNGIA, E. F. Work organization, conflict and aggression in an emergency hospital in São Paulo, Brazil. Rev. Ter. Ocup. Univ. São Paulo, v. 23, n. 3, p. 199-207, set./dez. 2012.

\begin{abstract}
The work in emergency rooms is distressing because of the conditions and work processes, high demand against the capacity and severity of the cases. This complicates the decisionmaking, individualizes the responsibilities, impacts on service and favors conflicts. It's our objective to investigate how the characteristics of work organization increases conflict and aggression in an emergency and to compromise care. This is a case study, exploratory and qualitative, it was used documentary evidence, semi-structured interviews and observation of the work, specifically, the porters. It was observed that the porters are on the front line and are exposed to pressure from users for assistance. They use their own criteria to solve conflicts, extrapolate rules and procedures, perform tasks beyond their competence, may change the flow and quality of care. The organizational arrangement disregards the porters as part of care staff by exposing them to conflict and aggression. It is expected contribute to change, improve relations, security and flow of service.
\end{abstract}

KEYWORDS: Emergency service, hospital; Work; Working conditions; Interpersonal relations; Aggression; Case studies; Emergency medical services/manpower.

\title{
REFERÊNCIAS
}

ABRAHÃO, J.; SZNELWAR, L.; SILVINO, A.; SARMET, M.; PINHO, D. Introdução à ergonomia da prática à teoria. São Paulo: Blucher, 2009.

ARNETZ, J. E.; ARNETZ, B. Violence towards health care staff and possible effects on the quality of patient care. Social Sci. Med., v. 52, n. 3, p. 417-427, 2001.

ATKINSON, S. Antropologia e pesquisa sobre qualidade dos serviços de saúde. Cad. Saúde Pública, v. 9, n. 3, p. 283-299, 1993. Disponível em: <http://www.scielo.br/pdf/csp/v9n3/16. pdf $>$.

COELHO, M. O; JORGE, M. S. B. Tecnologia das relações como dispositivo do atendimento humanizado na atenção básica à saúde na perspectiva do aceso, do acolhimento e do vínculo. Cienc. Saúde Coletiva, v. 15, n. 1, p. 1523-1531, 2009.

COLARES, L.G.T.; FREITAS, C.M. Processo de trabalho e saúde de trabalhadores de uma unidade de alimentação e nutrição: entre a prescrição e o real do trabalho. Cad. Saúde Pública, v. 23, n. 12, p. 3011-3020, 2007.

DESLANDES, S. F. Frágeis deuses: profissionais de emergência entre os danos da violência e a recriação da vida. Rio de Janeiro: Fiocruz, 2002.

DIAS, E. C. Organização da atenção à saúde do trabalhador. In: Ferreira MJ. Saúde no trabalho: temas básicos para o profissional que cuida da saúde dos trabalhadores. São Paulo: Roca, 2002. p.3-28.
EL-GILANY, A. H; EL-WHEHADY, A.; AMR, M. Violence against primary health care workers in Al-Hassa, Saudi Arabia. J. Interpersonal Violence, v. 25, n. 4, p. 716-734, 2010.

GONÇALVES, R. M. A. Estudo das estratégias operatórias desenvolvidas pelos agentes de fiscalização da Zona Azul na relação com os usuários do serviço - subsídios para o aprimoramento de um cotidiano de trabalho. São Paulo, 2009. [Dissertação] - Faculdade de Medicina da Universidade de São Paulo.

GOOSNEY, J.; HUTCHINGS, D.; LUNDRIGAN, E.; LYNCH, A.; MATHEWS, M. A risk Assessment screening tool for community health care workers. Home Health Care Management \&Practice Online First. 2009. Disponível em: $<$ http://hhc. sagepub.com/cgi/rapidpdf/1084822309348893v1.pdf> DOI: $10.1177 / 1084822309348893$

GRAHAM, J.; RAMIREZ, A. J. Mental health of hospitals consultants. J. Psychosom. Res., v. 43, n. 3, p. 227-231, 1997

GUERIN, F.; LAVILLE, A.; DANILLOU, F.; DURRAFOURG, J.; KEGUELEN, A. Compreender o trabalho para transformálo: a prática da ergonomia. São Paulo: Edgard Blücher, 2001.

INTERNATIONAL LABOUR ORGANIZATION (ILO). Introduction to violence at work. SafeWork-Violence at work. 2002, Disponível em: <http://www.ilo.org/public/english/ protection/safework/violence/index.htm $>$.

KENNEDY, P. Violence in emergency departments: under- 
reported, unconstrained and unconscionable. Med. J. Austr., v. 183, n. 7, p. $362-365,2005$.

LANCMAN, S.; GHIRARDI, M. I. G; CASTRO, E. D.; TUACEK, T. A. Repercussões da violência na saúde mental de trabalhadores do Programa de Saúde da Família. Rev. Saúde Publica, v. 43, n. 4, p. 682-688, 2009. Disponível em: <http://dx.doi.org/10.1590/ S0034-89102009005000036>.

LANCMAN, S.; MÂNGIA, E. F; MURAMOTO, M. T. Impact of situations of conflict and violence over workers of a hospital emergency departament. Work: J. Prevent. Assessm. Rehabil., 2011.

LANCMAN, S.; MÂNGIA, E. F.; GONÇALVES, R. M. A.; JARDIM, T.A. Violência no trabalho e saúde mental em um serviço de pronto atendimento hospitalar In: ASSUNÇÃO, A. A.; BRITO J. (Org.) Trabalhar na saúde: experiências cotidianas e desafios para a gestão do trabalho e emprego. Rio de Janeiro: Editora Fiocruz, 2011. p.111-130.

MELO, E. M. C; ASSUNÇÃO, A. A; FERREIRA, R. A. O trabalho dos pediatras em um serviço público de urgências: fatores intervenientes no atendimento. Cad. Saúde Pública, v. 23, n. 12, p.3000-3010, 2007.

SANTOS JR, E. A.; DIAS, E. C. Médicos vítimas da violência no trabalho em unidades de pronto atendimento. Cad. Saúde Coletiva, v. 13, n. 3, p. 705-722, 2005.

SCHRAIBER, L. B; PEDUZZI, M.; SALA, A.; NEMES, I. B.; CASTANHEIRA, E. R. L.; KON, R. Planejamento, gestão e avaliação em saúde: identificando problemas. Cien. Saúde Coletiva, v. 4, n. 2, p. 221-242, 1999.

SUNDQUIST, J. E.; JOHANSSON, S. E. High demand, low control, and impaired general health: working conditions in a sample of Swedish general practitioners. Scand. J. Public Health, v. 28 , n. 2, p. $23-31,2000$.

TOBIN, T. Organizational determinents of violence in the workplace. Agressive Violent Behav., v. 6, p. 91-102, 2001.

TRAD, L. A. B.; ROCHA, A. A. R. M. Condições e processo de trabalho no cotidiano do PSF: coerência com princípios da humanização em saúde. Cien. Saúde Coletiva, v. 16, n. 3, p. 1969-1980, 2011.

TURATO, E. R. Métodos qualitativos na área da saúde: definições, diferenças e seus objetos de pesquisa. Rev. Saude Publica, v. 39, n. 3, p. 507-514, 2005.

VASCONCELOS, E. M. Complexidade pesquisa interdisciplinar. São Paulo: Vozes, 2002.

Recebido para publicação: 15/06/2012

Aceito para publicação: 15/03/2013 